\title{
CULTURAL-HISTORICAL ACTIVITY THEORY AS A LENS IN MIXED METHODS RESEARCH ON SELF-DIRECTED LEARNING
}

\author{
E. Mentz* \\ https://orcid.org/0000-0002-7267-080X
}

\section{J. J. de Beer*}

https://orcid.org/0000-0002-2411-6599

${ }^{*}$ Research Unit Self-Directed Learning

North-West University

Potchefstroom, South Africa

\section{ABSTRACT}

Self-directed learning (SDL) has become a sine qua non in a complex twenty-first century, especially in a transformed world during and after the Covid-19 pandemic. In this article, the authors argue that the use of quantitative instruments alone to measure students' SDL is not rigorous enough to draw conclusions on the effectiveness of an intervention in an educational setting over a short period of less than a year. We suggest supplementing the quantitative data with qualitative data, and then utilizing cultural-historical activity theory (CHAT) as a research lens to provide a more nuanced understanding of the intervention and the effect thereof on students' SDL. We propose a model using third-generation CHAT to provide a thick description of the research findings.

Keywords: self-directed learning, mixed methods research, quantitative instruments, qualitative research, cultural-historical activity theory

\section{INTRODUCTION AND PROBLEM STATEMENT}

With the exponential growth in knowledge production, and the fact that school learners will one day fill occupations that do not exist today, there is an urgent need that self-directed learning (SDL) should be the gold standard in all educational sectors. The 2020 Covid-19 pandemic provided an unnerving realization that transmission-mode teaching and learning practices, which still dominate many educational interventions or sectors, should be replaced with approaches that would enhance SDL. Brandon (2020) calls SDL the "next wave for learning and development", that will gain momentum even after the global lockdown brought about by the Covid-19 pandemic. The pandemic also brought about the realization that universities need to evolve (Kupe 2020). The switch to online platforms did not only expose the glaring inequalities in education, but it also sensitized lecturers to the importance of nurturing self- 
directed learning. SDL can be defined as a process in which learners take responsibility for their own learning. This process can occur with or without the assistance of others, and comprises the identification of own learning needs, the formulation of learning goals, finding own resources and materials for learning, planning and implementing own learning by selecting the appropriate strategies, and evaluating the learning outcome (Knowles 1975). The evaluation of the learning outcomes includes the ability to define the criteria for self-evaluation and the reflection on the learning experience (Savicevic 2008). Learning to foster SDL should be organized in such a way that continued learning after completion of the educational activity is encouraged and stimulated (Savicevic 2008).

If one looks at the body of research in the field of SDL, it is clear that it is dominated by quantitative approaches (Tekkol and Demirel 2018), while only a limited number of mixed methods studies have been done. Several quantitative instruments have been developed to measure SDL, such as -

- $\quad$ the SDL readiness scale (SDLRS) developed and validated by Guglielmino (1977);

- the SDL readiness scale for nursing education (SDLRSNE) developed and validated by Fisher, King, and Tague (2001);

- $\quad$ the Williamson (2007) self-rating scale of SDL (SRSSDL);

- $\quad$ the SDL instrument (SDLI) developed and validated by Cheng et al. (2010); and

- $\quad$ the Oddi (1986) continuing learning inventory (OCLI).

A less-known and less-utilized instrument is that of Khiat (2015), a generic instrument, which serves as a diagnostic tool to identify students' strengths and weaknesses in areas of SDL. Cadorin, Bressan, and Palese (2017) state that Knowles's (1975) SDL theory served as the conceptual reference in the design of most of these instruments. This theoretical embeddedness is probably the reason why literature, in general, reflects positively on these instruments. However, there are also voices of criticism. Baveye (2003) is of the opinion that the SDLRS instrument remains "centered on the easily measured perceptions [our emphasis] of SDL readiness rather than on actual, observed SDL endeavors" $(2003,445)$, and that "quantitative research on SDL should be reoriented in an entirely different direction" $(2003,445)$. Northrup (1994) shows how difficult it is to validate or "record-check" studies that use questions to measure values, attitudes or beliefs. The above-mentioned instruments seem to be effective in measuring respondents' perceptions of their own SDL as well as long-term change in SDL. However, research also shows that these instruments are often not sensitive enough to measure 
more nuanced changes over shorter periods of time (Bosch 2017).

Very often, SDL research entails conducting interventional evaluations to see whether a particular intervention has resulted in more SDL. The predominant quantitative research approach falls short of providing a "thick description" of the influence of such interventions. Fetters and Molina-Azorin (2020) make a strong case that interventional studies should subscribe to mixed methods research. Authors such as Drabble and O'Cathain (2015) concur. According to Fetters and Molina-Azorin (2020, 132), mixed methods provide "organic unity" and an "integrated and dynamic approach" when evaluating interventions.

Over the past few years, several mixed methods research studies conducted by the NorthWest University (NWU) in South Africa (Bailey 2016; Bosch 2017; Lubbe 2015; Tredoux 2012) used different SDL questionnaires to measure the influence of specific active teachingand-learning strategies to enhance SDL. Bailey (2016) determined the effect of critical thinking development on the SDL of Grade 10 Information Technology learners. Utilizing a mixed methods research design in 25 schools, and the SDLI questionnaire (Cheng et al. 2010) as a measuring instrument in a pre- and post-test, Bailey (2016) found that SDL scores for all the groups were high in the pre-test. However, the four groups scored rather similar in the pre-test and in the post-test. In the qualitative investigations, however, several SDL themes emerged from the two experimental groups, indicating enhanced SDL skills among learners after the intervention. These themes were not pertinent in the quantitative data. Bosch (2017) also used the SDLI of Cheng et al. (2010) as an SDL measuring instrument across an experimental group and three control groups. Only one control group showed a medium practical significant difference between the pre- and post-test. No significant change occurred in the experimental group or the remaining control groups. The post-intervention qualitative data, however, indicated clear evidence that students realized that they were responsible for their own learning.

Lubbe (2015) utilized the SDLRS of Guglielmino (1977) to determine the influence of cooperative base groups on students' SDL readiness. Lubbe $(2015,132)$ concluded, "no practical significant difference was evident between students' SDL readiness scores before and after the cooperative base group intervention". The qualitative data, however, indicated several SDL learning competencies after completion of the intervention. Using the Fisher et al. (2001) SDL readiness scale for nursing education, Tredoux (2012) obtained similar results with no practical significant differences in SDL scores before and after the intervention. However, Tredoux (2012) also reported that the qualitative data indicated evidence of increased SDL skills and competencies after the intervention. The general trend observed was that these instruments often did not show gains in SDL attributes over a three- to six-month period, even after sound, innovative interventions to enhance SDL. 
Apart from the above NWU studies, a few international SDL research studies also used a mixed methods design. Two such studies are those of Premkumar and Banerjee $(2013 ; 2014)$, which aimed to determine whether medical training at the University of Saskatchewan promoted or discouraged SDL. After the first year of academic study, the students' SDL scores in answering Guglielmino's SDLRS instrument dropped significantly, and it did not pick up again over the period of study. In focus group interviews with the participants, it emerged that the learning culture and environment were not conducive to enhance SDL - a finding that could not be made on the strength of the quantitative data alone. Other mixed methods studies include those of Bartholomew (2016) and Kidane et al. (2020). Kidane et al. (2020) explored Ethiopian medical students' SDL. Williamson's (2007) SRSSDL was used, supplemented by focus group interviews. The qualitative data showed that the problem-based learning approaches and tutorial discussions had a considerable influence on students' SDL, and that lectures and summative assessments had a low influence on SDL ability - findings that would not have emerged if only the SRSSDL instrument had been used. In similar vein, Bartholomew (2016) did a mixed methods study in the United States of students' SDL during a middle school Science, Technology, Engineering and Mathematics (STEM) activity utilizing mobile devices. Bartholomew utilized the Modified Self-Directed Learning with Technology Scale quantitative instrument (Teo et al. 2010), supplemented with qualitative research approaches (portfolios and interviews). The qualitative data showed that students' SDL was independent of mobile device access.

We argue that quantitative instruments alone are not rigorous enough to measure SDL gains over a period and do not indicate the reasons for the quantitative results obtained. When analyzing qualitative results, we frequently obtain sound evidence from the qualitative data of student SDL readiness improvement even if quantitative results do not confirm the enhancement.

The discrepancy that sometimes occurs between the two datasets supports King, Keohane, and Verba's $(1994,105)$ argument that "slightly more complicated theory will explain vastly more of the world". Tarrow $(2004,101)$ further reasons that such theories could highlight "the relations between quantitative and qualitative approaches". However, the dichotomous nature that is sometimes displayed by quantitative and qualitative data, could lead to a "black box", which could provide the researcher with limited understanding, and much of the learning intricacies might go unexplained (Timans, Wouters, and Heilbron 2019).

In this article we want to indicate how cultural-historical activity theory (CHAT) could assist in opening the "black box", and address the "blind spot" that characterizes much of the current mixed methods research in SDL. We would like to show how CHAT could provide 
insight into apparent contradictions between quantitative and qualitative data. In a post-Covid19 world, such a CHAT lens could be appropriate to explore all the dynamics of blended learning in an unequal South African educational landscape. Whether SDL is enhanced during blended learning, depends on factors such as infrastructure and internet access, skills of students and staff, and the assessment processes and tools utilized (Saeed 2020). In addition, the enhancement of SDL also depends on the level of motivation of students to participate in their own learning, their willingness to take responsibility for their own learning, and the level of scaffolding provided by the facilitator, to name only a few aspects (Francom 2010; Brookfield 1988; Knowles 1975).

The research question underpinning this article therefore relates to how researchers could analyze and interpret these seemingly contradictory quantitative and qualitative findings, and how CHAT could be a useful lens to study the phenomenon. In this article, we will elaborate on CHAT as a lens to analyze pre- and post-intervention quantitative and qualitative data in educational research aimed at the enhancement of SDL. We argue that CHAT, derived from social constructivist theory, could offer a rigorous research lens to provide a "thick description" (Geertz 1973) of the relationship between quantitative and qualitative data in complex educational settings, such as in SDL environments, and illuminate factors influencing the enhancement (or impediment) of SDL.

However, before we focus on CHAT as a versatile lens in mixed methods SDL research, we first consider SDL, and the advantages of a mixed methods approach in SDL research.

\section{SELF-DIRECTED LEARNING: A SINE QUA NON IN A COMPLEX TWENTY-FIRST CENTURY}

In the twenty-first century with rapid change in knowledge production, as well as changes in how knowledge can be obtained, it is important for each citizen to learn how to attain new knowledge and how to apply it in similar or even different situations as a lifelong, self-directed learner. These new demands force the education system to restructure - especially in a post Covid-19 context. Conventional teaching methods where students were trained to memorize facts and represent them to pass examinations will not equip students for the rapidly changing world where data becomes outdated fast, and where unfamiliar problems increasingly need to be solved. Mok $(2013,8)$ is of the opinion that education in this century should be more than the transmission of knowledge; it should be to foster "knowledge creation, knowledge management, knowledge transfer and knowledge acquisition". The demands of the twenty-first century also require new skills to critically evaluate own learning and to reflect on it. This is why SDL is now even more important than three decades ago. Students need to take 
responsibility for their own learning and to direct their learning according to their own learning needs. Henschke $(2016,13)$ provides three reasons why SDL is an essential skill for today:

- Convincing evidence exists that people who are taking the initiative in their learning, learn more and better than those who are passively taught;

- $\quad \mathrm{SDL}$ is in line with human psychological development to take responsibility for their own learning; and

- New developments in education place a large emphasis on learners to take "initiative in their own learning".

Currently, in 2020, we can still concur with Knowles $(1975,15)$ that "it is tragic that we [still] have not learned how to learn without being taught". The sudden move from face-to-face teaching and learning to online teaching and learning during the COVID-19 pandemic, clearly showed the inequalities between learners who are able to take the responsibility for their own learning and those who cannot cope in this online environment, where they need to take responsibility by setting their own goals, finding suitable sources for learning and use appropriate strategies to reach these goals.

Knowles (1975) connected SDL to andragogical assumptions and processes, but never stated that SDL cannot be applied to school learners as well. Knowles $(1975,19-20)$ states that andragogy does not place the emphasis on teaching as pedagogy, as "pedagogy" typically is defined as teacher-directed. He then clearly states:

"Teacher-directed learning assumes the learner is essentially a dependent personality and that the teacher has the responsibility of deciding what and how the learner should be taught; whereas SDL assumes that the human being grows in capacity (and need) to be self-directing as an essential component of maturing, and that this capacity should be nurtured to develop as rapidly as possible" (Knowles 1975, 19-20).

SDL is underpinned by constructivist epistemology (Morris 2018). Constructivist learning environments involve learners in solving real-world problems. Morris (2018) is of the opinion that learners should be given the freedom to select information applicable to solve such problems. SDL is however much more complex. In the words of Guglielmino and Long (2011, 1), "[SDL] is recognized as a dynamic combination of attitudes and skills, essential for dealing with the complexity individuals face in all aspects of their live". Characteristics like persistence, curiosity, joy of learning, intrinsic motivation, volition and goal orientation (Guglielmino 1977; 1978; Knowles 1975) are but some of the important features to consider when determining the 
personal orientation towards SDL. Another aspect of SDL, which is often underemphasized or even negated, is the role of collaboration with others in SDL. Brockett (1994) calls the fact that some people view SDL as learning in isolation a myth and an incorrect stereotype. The fact that Knowles added the words "with or without the help of others" (Knowles 1975, 18) in his definition of SDL, already indicated the importance he placed on collaboration when learning. One of Knowles' nine competencies of SDL is the ability to work collaboratively with peers, as peers can act as resources for learning and provide assistance in planning, implementing and evaluation of learning. Peers can also assist in diagnosing learning needs. Even effective learning strategies never used or known by the learner can be introduced by peers or facilitators (Johnson and Johnson 2019). In an on-line teaching and learning environment, it asks for advanced skills from a teacher/lecturer to construct such constructivist and cooperative learning opportunities.

From the above discussion of SDL, it is clear that SDL is not only centered on the individual. The Person-Process-Context (PPC) model of Hiemstra and Brockett (2012) emphasizes that three elements - the person, the process and the context - should be seen as equally important in SDL. The "person" refers to the attributes and characteristics of the learner, the "process" refers to the teaching-learning transactions, such as planning, organizing and evaluating abilities, and the "context" encompasses the learning environment and sociopolitical climate (Hiemstra and Brockett 2012,158) - which will not necessarily be within an individual learning environment. Saeed (2020) refers to how the COVID-19 pandemic has revealed and exacerbated the inequality in higher education in South Africa. Whereas more privileged students could progress well with their studies in an online environment, many marginalized students in rural areas struggled with their studies due to contextual problems such as a lack of infrastructure and internet access, but also a lack of attributes associated with SDL. CHAT is very well aligned with this PPC model, as will be explained later. CHAT also provides a lens to look at SDL holistically.

It is thus obvious that SDL is not equal to self-study, and the complexity to study SDL in the learning environment increases even more because of the involvement of the "knowledgeable other". Brookfield (1988) also acknowledges the fact that SDL is far more complex than was expected at first. This is why the analysis of SDL research also needs a complex and versatile lens, such as CHAT - especially in a country like South Africa that struggles with inequality in higher education.

\section{THE AFFORDANCES OF A MIXED METHODS APPROACH IN SELF-DIRECTED LEARNING RESEARCH}

Mixed methods research can be considered the third methodological movement (Venkatesh, 
Brown, and Bala 2013), with quantitative and qualitative research respectively representing the first and second movements. As stated, quantitative approaches currently dominate SDL research. A quantitative purist would maintain that social science inquiry should be objective, and that time- and context-free generalizations should be made (Johnson and Onwuegbuzie 2004). Qualitative researchers again reject such positivism, and argue for the superiority of constructivism (Johnson and Onwuegbuzie 2004). However, mixed methods research combines the insights of quantitative and qualitative research into a "workable solution" (Johnson and Onwuegbuzie 2004). The latter authors (p. 18) claim that mixed methods research, embedded in pragmatism, "recognizes the ... importance of ... the natural or physical world as well as the emergent social and psychological world", and furthermore endorses fallibilism, since research conclusions are often not absolute. Venkatesh et al. (2013) list three value attributions of mixed methods research, namely -

- Its power to address confirmatory and exploratory research questions simultaneously;

- Its ability to provide stronger inferences than a single method or worldview; and

- Its ability to accommodate a greater range of divergent and/or complementary views.

Andrew and Halcomb (2007) as well as Salehi and Golafshani (2010) identify six purposes for using a mixed methods design, namely triangulation, complementarity, development, initiation, expansion and the ability to enhance significant findings. We will elaborate on this later when we frame the substantiation for CHAT as a lens in SDL mixed methods research around these purposes. Several authors in research methodology (Johnson and Onwuegbuzie 2004; Timans et al. 2019) show that mixed methods could result in a better understanding of the research object - especially where the object of study is a complex phenomenon, such as SDL. Mixed methods research ensures that a complete picture of the phenomenon is obtained, and that inferences are credible (Venkatesh et al. 2013). CHAT, we argue, provides a lens to aid such better understanding in a mixed methods research paradigm.

\section{CULTURAL-HISTORICAL ACTIVITY THEORY AS RESEARCH LENS TO INTERPRET DICHOTOMOUS QUANTITATIVE AND QUALITATIVE DATA}

CHAT is a robust meta-theoretical framework (Igira and Gregory 2009) that has been used especially in diverse societies, such as South Africa - to offer insights into systemic factors and tensions that influence (enhance or inhibit) specific educational objectives. It emerged from the work of the Russian psychologist Lev Vygotsky (1978), and was further developed by scholars such as Leont'ev (1981) and Engeström (1987). CHAT is especially valuable in complex 
research settings. Foot (2014) emphasizes the fact that an activity system is multi-voiced and multi-layered. According to Havnes (2010), human functioning is embedded in culture and history. Havnes $(2010,492)$ argues, "cultural embeddedness implies that human action and interaction cannot be understood without including social and cultural context in the analysis". Yamagata-Lynch (2010) highlights the advantage of CHAT to identify historical relationships among multiple activities and how previous activities could influence new activities. Engeström (1987) introduced the concept of an "activity system" to understand the socio-cultural context within which people are embedded and where they interact (Igira and Gregory 2009). An activity system could be a classroom, a community of practitioners or an informal learning environment - it is thus a useful research lens in the context of teaching and learning in a school context, higher education, the workplace, or even in informal education. For instance, De Beer and Mentz (2019) have used CHAT as a research lens to study self-directed learning amongst indigenous knowledge holders (Khoisan people, in marginalized communities in the Northern Cape). Within such an activity system, a multitude of relations exists (Foot 2001). In Figure 1, an SDL environment is presented as an activity system.

The most common way of using CHAT is on a personal level (Rogoff 1995), where the focus is on the individual learner as the subject, as shown in Figure 1. (CHAT can also be used on an inter-personal level, or on an institutional level, but the focus of this article is not on these distinctions. An example of utilizing CHAT on an institutional plane, is the comparison that Mentz and De Beer (2019) make between self-directed learning and indigenous knowledge systems, in order to determine whether the holders of indigenous knowledge were self-directed learners). In the activity system depicted in Figure 1, the object of the activity is the enhancement of SDL. "Tools" refer to artefacts, which the subject (learner) use in obtaining the object of the activity system (Foot 2014); thus, tools that could facilitate the development of SDL skills. In terms of the Hiemstra and Brockett (2012) PPC model, "tools" would also encompass parts of the "process", e.g., whether approaches, such as cooperative learning, enhance or deter SDL. "Rules" denote guidelines and policies that direct the activities and motivate or demotivate the subject. In this particular example, the five elements of cooperative learning (Johnson and Johnson 2016, 165), namely "positive interdependence", "individual accountability", "face-to-face promotive interaction", "interpersonal and small-group skills" as well as "group processing", would constitute some of the rules. The guidelines for fostering problem-based learning, e.g., having authentic problems to investigate and providing scaffolding and support (versus transmission-mode teaching) would constitute further rules. The rules in the activity system would also refer to "context", in Hiemstra and Brockett's (2012) PPC model. The "community" refers to all stakeholders in the activity system. In this case, the 
community consists of peers, experts and facilitators and might also be linked to Hiemstra and Brockett's (2012) "context". The division of labor refers to the different dimensions of the subjects' actions and involvement in the activity system, e.g., a self-directed learner should be a problem solver, a collaborator and a communicator who can reflect critically and resonate with the "person" in Hiemstra and Brockett's (2012) PPC model.

\section{Active learning \\ strategies (e.g. PBL, T \\ $\mathrm{CL})$, Internet}

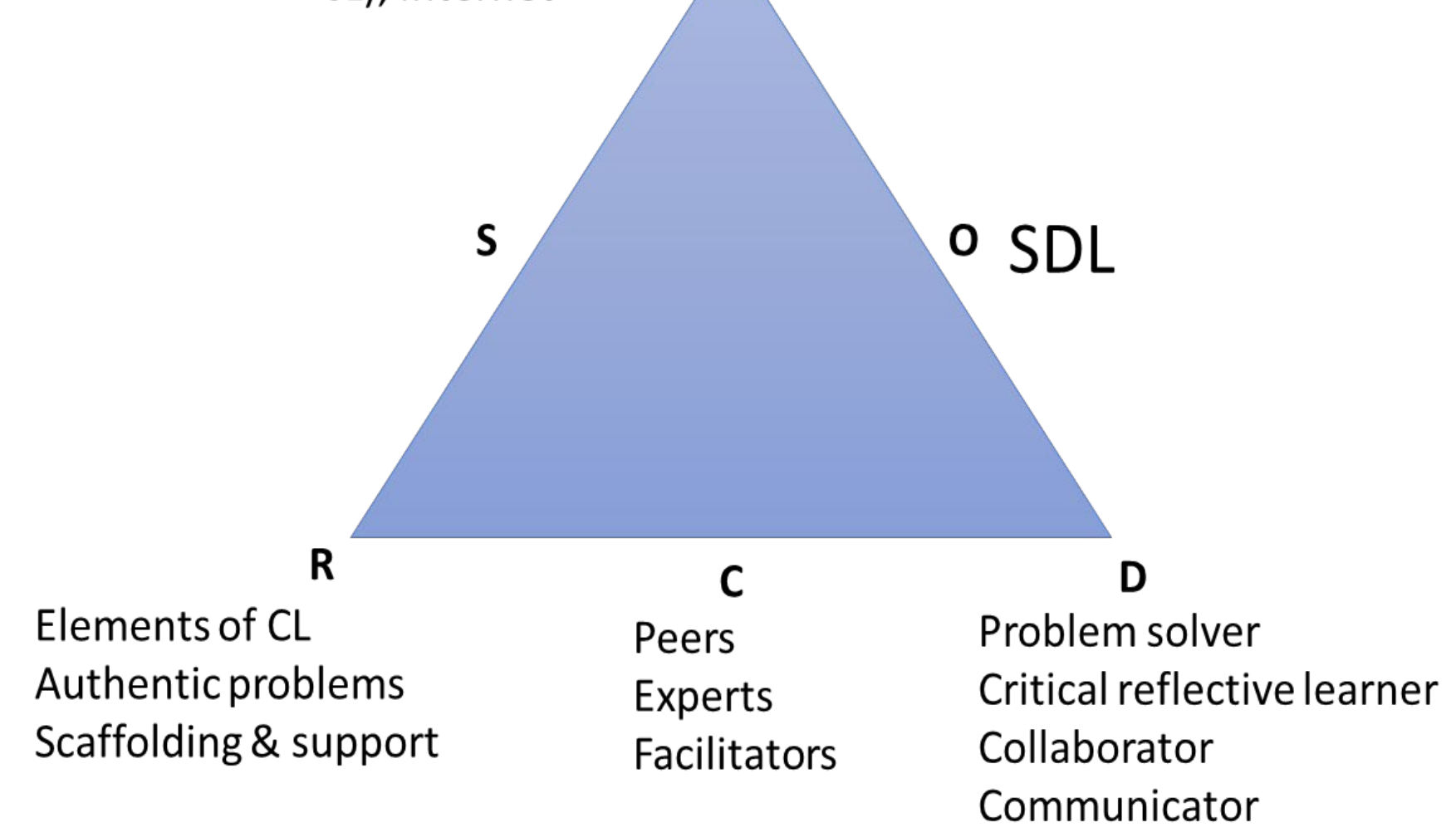

Figure 1: An SDL environment presented as an activity system illustrating the different signs, strategies and resources that support the nodes

As depicted in its name, a CHAT analysis emphasizes the importance of historical factors on the object (i.e., SDL) in the activity system. As an illustration, when analyzing Figure 1 as an activity system, the historic predominance of transmission mode teaching-and-learning practices in South Africa should be considered. The historical dominance of transmission-mode approaches often makes it difficult to witness educational reform in terms of SDL. Despite innovative interventions to foster active learning strategies that could enhance SDL, educators often revert to historic practices. To refer back to the PPC model of Hiemstra and Brockett (2012) mentioned earlier, CHAT provides a unique gaze into all three constructs in the model: 
the individual as self-directed learner, the process as well as the context necessary to enhance SDL. As Cole and Engeström (1993) observe, CHAT is deeply contextualized and oriented at understanding historically specific practices, their objects, mediating artefacts and social organization.

In this dynamic activity system, tensions can develop, which will be either an obstacle (making it difficult for the subject to attain the object) or an enabling influence (assisting the subject in attaining the object - in this case, SDL) (Yamagata-Lynch 2010). Foot (2001) emphasizes that a central tenet of activity theory is its acknowledgement of contradictions, conflict and discoordination in activity systems. Such an analysis allows a systemic and systematic approach to understand human activity in real-world complex environments. Foot $(2014,337)$ states, "the analysis of contradictions as illuminative hinges can open new vistas of understanding”. Yamagata-Lynch (2010) states four advantages of using CHAT as a research lens, namely CHAT -

- $\quad$ assists the researcher to work with a manageable unit of analysis;

- $\quad$ highlights systemic implications;

- $\quad$ provides insights into systemic contradictions and tensions; and

- $\quad$ provides an effective heuristic to communicate findings.

Engeström (2009) recommends that a researcher should use at least two interdependent activity systems as the minimum unit of analysis. Together with Cole (1988), Engeström (2001) developed third-generation CHAT, as illustrated in Figure 2.

The unit of analysis is always human activity in a specific context. In Figure 2, such human activities in two interdependent activity systems are juxtaposed. The activity system on the left portrays the traditional university lecture room in South Africa. By contrast, the activity system on the right illustrates the SDL university learning environment. A particular student can be a subject in both these activity systems, depending on the specific learning context created by the different nodes in the activity system.

CHAT provides a heuristic with which to analyze and explore the relationships between different nodes in an activity system over a relatively short period of time (Krugell 2019) - a finding that the statistical analysis of quantitative data alone cannot achieve.

Engeström (2011) indicates that CHAT is best used with "intermediate theories". If CHAT is seen as a lens in research, these intermediate theories act as "filters" when analyzing the data. 


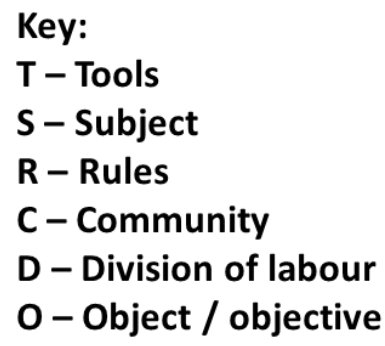

The traditional university lecture room
T Active learning strategies Internet

Research

S Student

Self0 Directed Learner

\section{D}

Problem solver

Critical reflective learner Experts

Collaborator

Communicator

Researcher

\section{C \\ Peers \\ Facilitators}

R

Elements of $\mathrm{CL}$ Authentic problems Scaffolding \& support
The SDL university learning environment

Figure 2: Third-generation CHAT where two activity systems are juxtaposed 

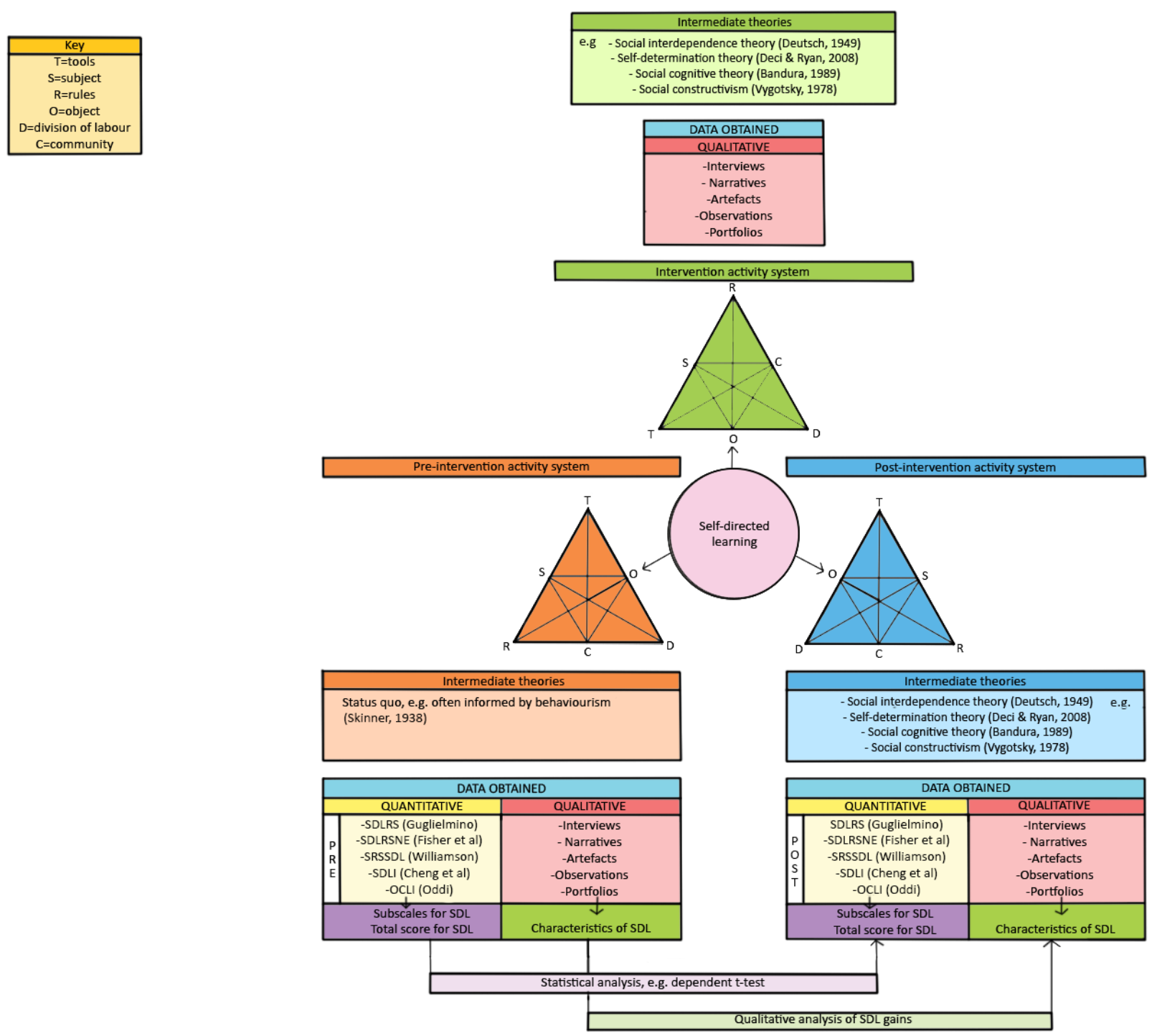

Figure 3: The model that we propose in SDL research 
Examples of such intermediate theories in terms of SDL are social interdependence theory (Deutsch 1949), self-determination theory (Deci and Ryan 2008), social cognitive theory (Bandura 1989) and social constructivist theory (Vygotsky 1978). By way of illustration, we could look at social interdependence theory, and its influence on SDL during the COVID-19 period in marginalized communities in South Africa. Johnson and Johnson $(2005,287)$ state that "social interdependence exists when outcomes of individuals are affected by each other's actions". Not all higher education students had access to online learning platforms during the pandemic (Saeed 2020), and in some cases universities had to post hard copies of learning material to such students. This means that these students, in their isolation, could not engage with "more knowledgeable others" (Vygotsky 1978), and thus could not jointly construct knowledge. CHAT as a research lens would expose the factors that could lead to the inhibition of SDL, such as a lack of support (absence of an effective "community"), lack of appropriate "tools" (e.g., computers and internet access), or the lack of skills to make best use of an on-line learning environment ("division of labour"). Most important though, is the lack of ability in the "subject" (student) to take responsibility for his/her own learning. These theories, in combination with CHAT, provide a robust framework for analyzing quantitative and qualitative data (Foot 2014).

In a study that explored the experiences of learners and teachers of case-based learning (as a form of problem-based learning) and its influence on SDL, Krugell (2019) utilized CHAT to analyze quantitative and qualitative data. He provided a thick description of factors that influence the SDL gains in dynamic and complex activity systems. CHAT as a research lens provided insight into systemic factors that eroded the enhancement of SDL. For example, in the quantitative SDLI questionnaire (Cheng et al. 2010), the "learning motivation" domain measured the highest in the experimental schools (schools where case studies were introduced in the teaching of Economics) during pre-intervention data collection (4.09, compared to 3.7 for "planning and implementing", 3.82 for "self-monitoring", and 3.71 for "interpersonal communication") (Krugell 2019, 126). Instead of the expected rise in post-intervention values, especially in terms of "learning motivation" - since case studies (for problem-based learning) are usually interesting and engaging - there was a significant drop in the "learning motivation" average of learners in the experimental schools in the post-test (namely 3.88). This was lower than the post-intervention average of the control schools (3.95) that were not exposed to casebased learning (in the control schools, the Economics learning content was taught using traditional methods). During the focus group interviews held after the intervention, learners generally held the opinion that they enjoyed participating in the case studies. It was, therefore, difficult at first to understand the drop in the average value for "learning motivation". CHAT 
as research lens provided additional insight into this contradictory finding by highlighting tensions between the different nodes. CHAT also provided a heuristic for the researcher in the interview process. In an attempt to understand the results better, Krugell (2019) explored the effect of the relationship between the "different nodes on learners" experiences. In the followup interviews, he asked questions related to possible tensions between nodes, e.g., the influence of rules or tools on the realization of the object. The learners indicated that they were frustrated that the teachers did not provide them with the "right" answers during the case studies. In casebased learning, cases should be ill-structured and learners should have to consider various (equally appealing) solutions to problems. In the interviews, the learners expressed their fears that this type of learning will not adequately prepare them for the examinations. They indicated that they preferred a teaching-learning approach where the teacher provides them with solutions or answers to problems. From a CHAT perspective, this finding makes sense, as the Grade 11 participants all had 11+ years' experience of predominantly transmission-mode teaching that prepared them to reproduce knowledge in the examination. The CHAT analysis indicated that learner motivation was linked to academic achievement, and the enjoyment they experienced with case-based learning did not contribute to their motivation (Krugell 2019). CHAT also highlighted the misalignment between the pedagogies used (problem-based learning and casebased learning) and assessment methods, which did not focus on problem solving, but on lowerorder regurgitation from learners.

\section{MEASURING CHAT AGAINST THE PURPOSES OF MIXED METHODS DESIGN}

Andrew and Halcomb (2007) as well as Salehi and Golafshani (2010) formulated six purposes for using mixed methods design. We would like to discuss CHAT as research lens in relation to these purposes. In addition, we also discuss CHAT in terms of Pinch and Bijker's (1984, 399) "interpretative flexibility", and the role it could play in ensuring interpretive rigor and inference quality (Tashakkori and Teddlie 2003).

\section{(a) Triangulation}

Creswell and Miller $(2000,126)$ define triangulation as "a validity procedure where researchers search for convergence among multiple and different sources of information to form themes or categories in a study". CHAT provides a unique view of both quantitative and qualitative data (see Figure 3), and provides a lens to study the inherent tensions between the different nodes in an activity system.

\section{(b) Complementarity}

Doing triangulation results in complementarity, where the quantitative methods could enhance 
the findings of the qualitative methods further, and vice versa. CHAT provides a unique insight into the complementarity of the quantitative and qualitative data sets by integrating qualitative and quantitative results into one activity system for analysis purposes.

\section{(c) Development}

The quantitative and qualitative methods inform one another, and could shape succeeding methods. For example, in Krugell's (2019) study discussed earlier, the mismatch between the quantitative and qualitative data in terms of "learning motivation" highlighted during the CHAT analysis, resulted in a second set of focus group interviews conducted, not envisaged when the study was designed.

\section{(d) Initiation}

Initiation intends to raise new research questions, or challenge the findings obtained from a particular method. It entails exploring contradictions and new hypotheses. CHAT provides an excellent vehicle for such initiation. For example, in Krugell's (2019) study, teachers generally commented on how they appreciated the "energy" and active engagement of learners during case studies. However, they also shared their fear that it might not prepare learners adequately for summative assessment opportunities. As a sequel to the original interviews with teachers, informal interviews were conducted two months after the intervention, to determine whether teachers continued to use case studies as pedagogy. The findings were that all the teachers reverted to "chalk-and-talk" approaches, due to the systemic factors that CHAT clearly highlighted, such as community expectations (good performance in summative assessments), a rigid curriculum with tight timeframes, as well as the lack of teacher experience in developing new case studies for use in the classroom.

\section{(e) Expansion and enhancing significant findings}

Due to the similarity in these two purposes, we discuss it jointly. The use of CHAT as a research lens to analyze quantitative and qualitative data and findings further, "expand the study for other opportunities or possibilities. This will provide depth and detail to the study" (Salehi and Golafshani 2010, 188).

\section{(f) Interpretative flexibility and the development of meta-inferences}

"Interpretative flexibility", a construct coined by Pinch and Bijker (1984, 399), refers to the manifestation that empirical observations allow for different interpretations to a certain degree (Meyer and Schulz-Schaeffer 2006). Often, different interpretations of the data and/or findings 
are possible, and CHAT provides a nuanced lens for such elucidation. It assists in the development of meta-inferences (Venkatesh et al. 2013). The latter authors (p. 38, 39) describe meta-inferences as "theoretical statements, narratives, or a story inferred from the integration of findings from quantitative and qualitative strands of mixed methods research ... metainferences are essentially statements about a phenomenon, its interrelated components, and boundary conditions". CHAT, as a research lens, excels in showing the causal effects of one node in an activity system on another. The fact that different "person", "process" and "context" variables could influence the effectiveness of SDL, is highlighted by CHAT as lens, and this provides insight into factors that either enhance or inhibit SDL in the activity system.

\section{(g) Inference quality and CHAT}

Creswell and Clark $(2007,145)$ warn, "the very act of combining qualitative and quantitative approaches raises additional validity issues". Tashakkori and Teddlie (2003) recommend the term "inference quality" to refer to validity in mixed methods research. Inference in mixed methods studies is described by Tashakkori and Teddlie $(2003,692)$ as "a researcher's construction of the relationships among people, events, and variables as well as his or her construction of respondents' perceptions, behavior, and feelings and how these relate to each other in coherent and systematic manner". Venkatesh et al. $(2013,35)$ further explain inference quality as "the accuracy of inductively and deductively derived conclusions" in a research study. Inference quality consists of design quality and interpretive rigor (Tashakkori and Teddlie 2003). We argue that CHAT enhances both the design quality of a study as well as its interpretive rigor, due to its taxonomical character, which enriches the systematic analysis. We have already demonstrated how CHAT enhanced both the study design and interpretive rigor in Krugell's (2019) study. Figure 3 shows how CHAT as research lens utilizes intermediate theories as "filters" in analyzing quantitative and qualitative findings further, to show relationships and contradictions between the different data sets, and to provide a "thick description" (Geertz 1973) of the research object.

\section{CONCLUSION}

Quantitative measuring instruments for SDL tend not to show nuanced improvement in SDL over short periods when pre- and post-tests are used. Within educational settings, these nuanced improvements - even if they cannot be measured quantitatively - can be of value by informing future endeavors to enhance SDL. We suggest utilizing qualitative data to supplement quantitative data, and to utilize CHAT as a lens in such mixed methods studies to provide insight - not only into the enhancement of SDL but also into the factors contributing to the enhancement, or factors inhibiting SDL. As illustrated earlier on in this article, CHAT could 
specifically interrogate factors that impede SDL related to the inequalities characterizing South African education. An example is marginalized rural students, who do not have internet access to benefit from online- or blended learning, and those who lack motivation to take responsibility for their own learning.

The utilization of quantitative and qualitative methods could result in dichotomous data, and CHAT holds much affordance to open this "black box" (Timans et al. 2019), and to provide a nuanced meta-inference in the research. Given the complexity of SDL and all the variables at play in learning contexts - including cultural and historical factors - a sophisticated and robust meta-theoretical framework and lens are needed. CHAT, we claim, provides such a framework and lens. CHAT is well aligned with the PPC model of Hiemstra and Brockett (2012) and, whereas quantitative SDL instruments mostly focus on the "person", CHAT provides a glimpse into tensions that are created by integrating the "person", "process" and "context", to determine whether these enhance or inhibit SDL. In conclusion, educational research could benefit from the use of CHAT as a lens to analyze and gain insight into more nuanced views of SDL, factors contributing to SDL and variables likely to affect SDL attributes.

\section{REFERENCES}

Andrew, S. and E. J. Halcomb. 2007. "Mixed methods research is an effective method of enquiry for community health research." Journal for the Australian Nursing Profession 23(2): 145-153.

Bailey, R. 2016. “Developing Information Technology learners' critical thinking skills: Implications for self-directed learning." Unpublished doctoral thesis. North-West University, Potchefstroom.

Bandura, A. 1989. "Human agency in social cognitive theory." American Psychologist 44(9): 11751184.

Bartholomew, S. 2016. "A mixed-method study of mobile devices and student self-directed learning and achievement during a middle school STEM activity." Unpublished doctoral thesis. Utah State University, Logan, UT.

Baveye, P. 2003. "Refocusing the self - directed learning debate." Family Medicine 35(6): 445-446.

Bosch, C. 2017. "Promoting self-directed learning through the implementation of cooperative learning in a higher education blended learning environment." Unpublished doctoral thesis. North-West University, Potchefstroom.

Brandon, B. 2020. Are you ready? SDL is the next wave for $L \& D$. https://learningsolutions mag.com/articles/are-you-ready-self-directed-learning-is-the-next-wave-for-1-d (Accessed 8 November 2020).

Brockett, R. G. 1994. "Resistance to self-direction in adult learning: Myths and misunderstandings." In Overcoming resistance to self-direction in adult learning, ed. R. Hiemstra and R. G. Brockett, 512. San Francisco, CA: Jossey-Bass.

Brookfield, S. D. 1988. "Conceptual, methodological and practical ambiguities in self-directed leaning." In Self-directed learning: Application and theory, ed. H. B. Long, 1-10. Athens, GA: Department of Adult Education, University of Georgia.

Cadorin, L., V. Bressan, and A. Palese. 2017. "Instruments evaluating the self-directed learning abilities among nursing students and nurses: A systematic review of psychometric properties." $B M C$ Medical Education 17(229): 1-13.

Cheng, S.-F., C.-L. Kuo, K.-C. Lin, and J. Lee-Hsieh. 2010. "Development and preliminary testing of a 
self-rating instrument to measure self-directed learning ability of nursing students." International Journal of Nursing Studies 47: 1152-1158.

Cole, M. 1988. "Cross-cultural research in the sociohistorical tradition." Human Development 31: 137157.

Cole, M. and Y. Engeström. 1993. "A cultural-historical approach to distributed cognition." In Distributed cognitions: Psychological and educational considerations, ed. G. Salomon, 1-46. Cambridge, NY: Cambridge University Press.

Creswell, J. W. and V. L. P. Clark. 2007. Designing and conducting mixed methods research. Thousand Oaks, CA: Sage.

Creswell, J. W. and D. L. Miller. 2000. "Determining validity in qualitative inquiry." Theory into Practice 39: 124-130.

De Beer, J. and E. Mentz. 2019. The affordances of indigenous knowledge in decolonising the curriculum, within a self-directed learning framework. In The decolonisation of the curriculum project: The affordances of indigenous knowledge for self-directed learning, ed. J. de Beer. Cape Town, AOSIS.

Deci, E. L. and R. M. Ryan. 2008. "Self-determination theory: A macro theory of human motivation, development and health." Canadian Psychology 49(3): 182-185.

Deutsch, M. 1949. “A theory of co-operation and competition." Human Relations 2(2): 129-152.

Drabble, S. J. and A. O'Cathain. 2015. "Moving from randomized controlled trials to mixed methods intervention evaluations." In The Oxford handbook of mixed and multi method research, ed. S. Hesse-Biber and R. B. Johnson, 406-425. Washington, DC: Oxford University Press.

Engeström, Y. 1987. Learning by expanding: An activity-theoretical approach to developmental research. Helsinki: Orienta-Konsultitl.

Engeström, Y. 2001. "Making expansive decisions: An activity-theoretical study of practitioners building collaborative medical care for children." In Decision making: Social and creative dimensions, ed. C. Allwood and M. Selart, 281-301. Dordrecht: Springer.

Engeström, Y. 2009. "From learning environments and implementing to activity systems and expansive learning." Actio: An International Journal of Human Activity Theory 2(1): 17-33.

Engeström, Y. 2011. "From design experiments to formative interventions." Theory \& Psychology 21(5): 598-628.

Fetters, M. D. and J. F. Molina-Azorin. 2020. "Utilizing a mixed-methods approach for conducting interventional evaluations." Journal of Mixed Methods Research 14(2): 131-144.

Fisher, M., J. King, and G. Tague. 2001. "Development of a self-directed learning readiness scale for nursing education." Nurse Education Today 21(7): 516-525.

Foot, K. 2001. "Cultural-historical activity theory: Illuminating the development of a conflict monitoring network." Communication Theory 11(1): 56-83.

Foot, K. 2014. "Cultural-historical activity theory to inform practice and research." Journal of Human Behavior in Social Environment 24(3): 329-347.

Francom, G. M. 2010. "Teach me how to learn: Principles for fostering students' self-directed learning skills." International Journal of Self-directed Learning 7(1): 29-44.

Geertz, C. 1973. "Thick description: Toward an interpretative theory of culture." In The interpretation of cultures, ed. C. Geertz, 3-30. New York, NY: Basic Books.

Guglielmino, L. M. 1977. "Development of the self-directed learning readiness scale." Unpublished doctoral dissertation. University of Georgia, Athens, GA.

Guglielmino, L. M. 1978. "Development of the self-directed learning readiness scale". Dissertation Abstracts International 38(11-A): 6467.

Guglielmino, L. M. and H. B. Long. 2011. "Perspectives: The International Society for Self-Directed Learning and the International Self-Directed Learning Symposium." International Journal of Self- 
Directed Learning 8(1): 1-6.

Havnes, A. 2010. "Cultural-historical activity theory." In International encyclopaedia of education, ed. P. Peterson, E. Baker, and B. McGaw, 491-497. $3^{\text {rd }}$ Edition. Oxford: Elsevier.

Henschke, J. A. 2016. Self-directed learning and andragogy: My take on their contrasting and complementary relationship. International Adult and Continuing Education Hall of Fame Repository. University of Tennessee. https://trace.tennessee.edu/utk_IACE-browseall/477/.

Hiemstra, R. and R. G. Brockett. 2012. "Reframing the meaning of self-directed learning: An updated model." In Proceedings of the Adult Education Research Conference, 155-161. Saratoga Springs, NY. http://newprairiepress.org/aerc/2012/papers/22.

Igira, F. T. and J. Gregory. 2009. "Cultural-historical activity theory." In Handbook of research on contemporary theoretical models in information systems, ed. Y. K. Dwivedi, B. Lal, M. D. Williams, S. L. Schneberger, and M. Wade, 434-454. Hershey: IGI Global.

Johnson, D. W. and R. Johnson. 2005. "New developments in social interdependence theory." Genetic, Social and General Psychology Monographs 131(4): 285-358.

Johnson, D. W. and R. Johnson. 2016. "Cooperative learning and teaching citizenship in democracies." International Journal of Educational Research 76: 162-177.

Johnson, D. W. and R. T. Johnson. 2019. "The impact of cooperative learning on self-directed learning." In NWU Self-Directed Learning Series Vol. 1: Self-directed learning for the 21st century: Implications for higher education, ed. E. Mentz, J. de Beer, and R. Bailey, 37-66. Cape Town: AOSIS. doi:10.4102/aosis.2019.BK134.02.

Johnson, R. B. and A. J. Onwuegbuzie. 2004. "Mixed methods research: A research paradigm whose time has come." Educational Researcher 33(7): 14-26.

Khiat, H. 2015. "Measuring self-directed learning: A diagnostic tool for adult learners." Journal of University Teaching and Learning Practice 12(2): 1-15.

Kidane, H. H., H. Roebertsen, and C. P. M. Van der Vleuten. 2020. "Students' perceptions towards SDL in Ethiopian schools with new innovative curriculum: A mixed-method study." BMC Medical Education 20(7): 1-10.

King, G., R. O. Keohane, and S. Verba. 1994. Designing social inquiry. Scientific inference in qualitative research. Princeton, NJ: Princeton University Press.

Knowles, M. 1975. Self-directed learning: A guide for learners and teachers. New York, NY: Associated Press.

Krugell, J. F. 2019. "Die rol van gevallestudies in die bevordering van selfgerigte leer in Ekonomieonderrig op skool." [The role of case studies in promoting self-directed learning in Economics teaching at school]. Unpublished doctoral thesis. North-West University, Potchefstroom.

Kupe, T. 2020. "Covid-19 highlights the need for universities to evolve." University World News. https://www.universityworldnews.com/post.php?story=20200902142707290 (Accessed 8 November 2020).

Leont'ev, A. N. 1981. Problems of the development of the mind. Moscow: Progress Publishers.

Lubbe, A. 2015. "Cooperative base groups in higher education: The impact on Life Sciences students' self-directed learning readiness." Unpublished MEd dissertation. North-West University, Potchefstroom.

Mentz, E. and J. de Beer. 2019. "The use of Cultural-Historical Activity Theory in researching the affordances of indigenous knowledge for self-directed learning." In The decolonisation of the curriculum project: The affordances of indigenous knowledge for self-directed learning, ed. J. de Beer. Cape Town, AOSIS.

Meyer, U. and I. Schulz-Schaeffer. 2006. "Three forms of interpretative flexibility." Science, Technology and Innovation Studies Special issue, July: 25-40.

Mok, M. M. C. 2013. "Assessment reform in the Asia-Pacific region: The theory and practice of selfdirected learning." In Self-directed learning oriented assessments in the Asia-Pacific, ed. M. M. 
C. Mok, 3-22. Dordrecht: Springer.

Morris, T. H. 2018. "Vocational education of young adults in England: A systemic analysis of teaching - learning transactions that facilitate self-directed learning." Journal of Vocational Education \& Training. Advance online publication. doi: 10.1080/13636820.2018.1463280.

Northrup, D. A. 1994. "The problem of self-report in survey research.” The Institute for Social Research Newsletter 11(3): n.p.

Oddi, L. F. 1986. "Development and validation of an instrument to identify self-directed continuing learners." Adult Education Quarterly 36(2): 97-107.

Pinch, T. J. and W. E. Bijker. 1984. "The social construction of facts and artefacts: How the sociology of science and the sociology of technology might benefit each other." Social Studies of Science 14(3): 399-441.

Premkumar, K. and A. Banerjee. 2013. "Does medical training promote of deter self-directed learning? A longitudinal mixed-methods study." Academic Medicine 88(11): 1754-1764.

Premkumar, K. and A. Banerjee. 2014. "Changes in self-directed learning readiness in dental students: A mixed-methods study." Journal of Dental Education 78(6): 934-943.

Rogoff, B. 1995. Apprenticeship in thinking: Development in social context. Cambridge, MA: Harvard University Press.

Saeed, S. 2020. "Covid-19 has exacerbated inequality in higher education." University World News. https://www.universityworldnews.com/post.php?story=20201023103200335 (Accessed 8 November 2020).

Salehi, K. and N. Golafshani. 2010. "Using mixed methods in research studies: An opportunity with its challenges.” International Journal of Multiple Research Approaches 4: 186-191.

Savicevic, D. 2008. "Convergence or divergence of ideas on andragogy in different countries." International Journal of Lifelong Education 27(4): 361-378.

Tarrow, S. 2004. "Bridging the quantitative-qualitative divide." In Rethinking social inquiry: Diverse tools, shared standards, ed. H. E Brady and D. Collier, 101-110. Lanham, MD: Rowman and Littlefield.

Tashakkori, A. and C. Teddlie. 2003. "The past and the future of mixed methods research: From 'methodological triangulation' to 'mixed methods designs'." In Handbook of mixed methods in social and behavioral research, ed. A. Tashakkori and C. Teddlie, 671-701. Thousand Oaks, CA: Sage.

Tekkol, I. A. and M. Demirel. 2018. "An investigation of self-directed learning skills of undergraduate students.” Frontiers in Psychology 9(2324): 1-14. doi:10.3389/fpsyg.2018.02324.

Teo, T., S. C. Tan, C. B. Lee, C. S. Chai, J. H. L. Koh, W. L. Chen, and H. M. Cheah. 2010. "The selfdirected learning with technology scale (SDLTS) for young students: An initial development and validation." Computers and Education 55(4): 1764-1771.

Timans, R., P. Wouters, and J. Heilbron. 2019. "Mixed methods research: What it is and what it could be." Theory and Society 48: 193-216.

Tredoux, C. 2012. "The potential of a learning management system to enhance self-directed learning." Unpublished MEd dissertation. North-West University, Potchefstroom.

Venkatesh, V., S. A. Brown, and H. Bala. 2013. "Bridging the qualitative-quantitative divide: Guidelines for conducting mixed methods research in information systems." MIS Quarterly 37(1): 21-54.

Vygotsky, L. S. 1978. Mind in society. Cambridge, MA: Harvard University Press.

Williamson, S. N. 2007. "Development of a self-rating scale of self-directed learning." Nurse Research 14(2): 66-83.

Yamagata-Lynch, L. 2010. Activity systems analysis methods: Understanding complex learning environments. New York, NY: Springer. 